Available online: July 2018

\title{
UJI AKTIVITAS ANTIOKSIDAN FRAKSI ETIL ASETAT DAUN SALAM (Syzygium polyanthum) DAN UJI BILANGAN PEROKSIDA-NYA TERHADAP MINYAK GORENG CURAH
}

\author{
Vritta Amroini Wahyudi ${ }^{*}$, Afifah Nuril Aini ${ }^{2)}$, Dian Puspita 2), Ayu Ramadhanni \\ Kumala Dewi ${ }^{3)}$
}

1) Food science and technology department, Agriculture and Animal Science Faculty, Muhammadiyah University of Malang, Indonesia

2) Collage Food science and technology department, Agriculture and Animal Science Faculty, Muhammadiyah University of Malang, Indonesia

Choresponding author:vritta@umm.ac.id

\begin{abstract}
Cooking oil is a necessity of the people of Indonesia that is always needed. Based on the stages of manufacture, oil is divided into two, namely branded oil and bulk oil. Until now, branded oil is still the main choice even though it is economically more expensive than bulk oil. This is related to the tendency of bulk oil to experience rancidity due to oxidation reactions. The quality of bulk oil can be scientifically improved by the addition of antioxidants. Commonly used antioxidants are synthetic antioxidants such as TBHQ. Natural antioxidants are less popular because they have only stalled in the study but have not been compared significantly with synthetic antioxidants. In this study, a research is used to find out the stability of bulk oil with the addition of bay leaf ethyl acetate fraction and as a comparison of the use of TBHQ. Analysis of antioxidant activity of DPPH method was also used to find out determine the relationship between the power of antioxidant activity with the quality of bulk cooking oil. The evaluation was performed on the addition of bay leaf extract with various concentrations treated on bulk oil by heating for 20 minutes using $90^{\circ} \mathrm{C}$ temperature. The results showed that the bay leave ethyl acetate fraction has IC50 value of 19.473 ppm, so it can effectively reduce the number of peroxide. The smallest peroxide number was obtained at treatment P6 (1\%) that is 5,304 meqO2 / kg, where TBHQ (0,2\%) as comparison have value equal to 4,147 meqO2/ kg. This shows that the antioxidant activity is very strong in bay leaf significantly affect the inhibition of bulk oil destruction. Natural antioxidant from bay leaf can prevent bulk oil from oxidation as well as synthetic antioxidants, but safer than synthetic antioxidants.
\end{abstract}

Keywords: antioxidant activity, bay leave, peroxide test, bulk oil

\section{Pendahuluan}

Minyak goreng merupakan salah satu kebutuhan masyarakat Indonesia untuk mendukung kegiatan sehari-hari. Berdasarkan proses pembuatannya minyak goreng terbagi menjadi dua yaitu, minyak goreng kemasan bermerk (melalui proses bleaching atau pemutihan) dan minyak goreng curah (tidak melalui proses bleaching) (Widayat, 2006). Minyak goreng curah tidak melalui proses bleaching sehingga dikhawatirkan lebih cenderung mengalami rensiditas atau ketengikan dibandingkan dengan minyak goreng kemasan. Kecenderungan minyak goreng 
mengalami rensiditas berhubungan dengan terjadinya reaksi oksidasi (Winarno, 2004).

Jika dilihat dari segi ekonomi, minyak goreng curah sebenarnya memiliki harga yang relatif lebih terjangkau dibandingkan dengan minyak goreng kemasan. Rata-rata harga minyak goreng curah adalah $\mathrm{Rp} 11.405 / \mathrm{kg}$ sedangkan rata-rata harga minyak goreng kemasan adalah Rp 16.766/kg (Badan Pusat Statistik, 2013). Harga yang terjangkau tersebut ternyata tidak terlalu berpengaruh di persentasi pangsa pasar. Survey pasar sebelumnya menunjukkan angka $30 \%$ untuk persentase penjualan minyak goreng curah, sisanya yaitu $70 \%$ dikuasai oleh minyak goreng kemasan (Fadhila, 2008). Fakta ini menarik karena menunjukkan bahwa tingkat kepercayaan masyarakat untuk menggunakan minyak goreng kemasan lebih tinggi dibandingkan dengan minyak goreng curah. Artinya, masyarakat merasa kualitas minyak goreng curah masih tertinggal dengan minyak goreng kemasan.

Kualitas minyak goreng curah secara kimia, dapat ditingkatkan dengan penambahan zat antioksidan sehingga tidak mudah mengalami ketengikan. Zat antioksidan berdasarkan sumbernya terbagi menjadi antioksidan sintetik dan alami. Zat antioksidan sintetik antara lain butylated hydroxytoluene (BHT), butylated hydroxyanisole (BHA), propyl gallate (PG) dan tertiarybutyl hydroxyquinone (TBHQ) (Casarotti \& Jorge, 2014). Zat antioksidan sintetik memiliki potensi toksik (Hou,2003) serta karsinogenesis (Sibuea, 2003) sehingga antioksidan alami memiliki peluang untuk dieksplorasi.

Eksplorasi dapat dimulai dari tanaman yang memiliki potensi sebagai antioksidan. Penelitian sebelumnya telah menguji aktivitas ekstrak daun salam dengan hasil konsentrasi penghambatan $\left(\mathrm{IC}_{50}\right)$ sebesar 11,001 ppm, lebih tinggi dibandingkan dengan vitamin $\mathrm{C}$ (sebagai kontrol positif) sebesar 9,898 ppm. Hasil tersebut berhubungan dengan kandungan senyawa metabolit sekunder di dalamnya flavonoid, saponin, tanin, dan alkaloid (Bahriul, 2014).

Berdasarkan penjelasan tersebut maka penelitian eksplorasi senyawa metabolit sekunder pada ekstrak daun salam sebagai antioksidan alami untuk meningkatkan kualitas minyak goreng curah menjadi hal yang sangat menarik. Lebih lanjut lagi, untuk mengerucut pada golongan flavonoid, saponin, tanin, dan alkaloid, diperlukan tahapan fraksinasi menggunakan pelarut semipolar seperti etiil asetat. Tujuan dari penelitian ini untuk menguji ativitas antioksidan fraksi etil asetat dan uji bilangan peroksidanya terhadap minyak goreng curah. Selain itu, uji kualitatif golongan metabolit sekunder dapat mendukung analisis dan penarikan kesimpulan dari uji kualitas tersebut. 


\section{METODE PENELITIAN}

\section{Alat dan Bahan}

Alat-alat yang digunakan dalam penelitian ini antara lain spektrofotometer UV-Vis merk SHIMADZU, neraca analitik, labu erlenmeyer, satu set alat titrasi, pipet ukur, rotary vacum evaporator, tabung reaksi, beaker glass, pisau, saringan, botol selai, pengaduk, aluminium foil, blender dan wadah maserasi. Bahan yang digunakan dalam pembuatan daun salam dari Kebun Agung, Malang Jatim.

\section{Rancangan Penelitian}

\section{Ekstraksi dan Fraksinasi Daun Salam}

Sebanyak 4,8 kg daun salam diangin-anginkan hingga kering kemudian dihaluskan sampai menjadi simplisia. Simplisia dimaserasi dengan aseton selama 3 x 24 jam. Hasil maserasi disaring untuk didapatkannya filtrat dan residu. Filtrat yang diperoleh dihilangkan pelarutnya dengan rotary evaporator hingga diperoleh ekstrak kasar daun salam. Ekstrak kasar daun salam difraksinasi dengan corong pisah menggunakan $n$-heksana, etil asetat, dan metanol. Fraksi etil asetat diambil dan dihilangkan pelarutnya kembali menggunakan rotary evaporatorsampai diperoleh ekstrak fraksi etil asetat.

\section{Uji Kualitatif Metabolit Sekunder}

Uji dilakukan di Laboratorium Fitokimia UPT Materia Medica Batu. Uji dilakukan untuk empat golongan yaitu, uji kualitatif untuk flavonoid, saponin, tanin, dan alkaloid.

\section{Uji Kualitatif Flavonoid}

Sebanyak $2 \mathrm{~mL}$ sampel ditambahkan $8 \mathrm{~mL}$ akuades yang telah dipanaskan selama \pm 10 menit. Filtrat disaring dan dimasukkan ke dalam tabung reaksi kemudian ditambahkan $\mathrm{HCl}$ pekat beberapa tetes. Fraksi kemudian diitambahkan lagi dengan sedikit serbuk Mg. Hasil positif : warna merah tua, merah muda, merah bata.

\section{Uji Kualitatif Saponin}

Sebanyak $2 \mathrm{~mL}$ sampel ditambahkan $8 \mathrm{~mL}$ aquadest yang telah dipanaskan selama \pm 10 menit. Filtrat disaring dan dimasukkan ke dalam tabung reaksi. Fraksi ditambahkan $2 \mathrm{~mL}$ air panas lalu dikocok kuat. Hasil positif : terbentuk buih permanen selama tidak kurang dari 10 menit setinggi 1-10 cm, kemudian ditambahkan $\mathrm{HCl}$ pekat 1 tetes. Hasil positif lanjutan : busa permanen tidak hilang

\section{Uji Kualitatif Tanin}

Sebanyak $2 \mathrm{~mL}$ sampel ditambahkan $8 \mathrm{~mL}$ aquadest yang telah dipanaskan selama \pm 10 menit. Filtrat disaring dan dimasukkan ke dalam tabung reaksi, ditambahkan 3 tetes FeCl3 1\%. Hasil positif : warna coklat kehitaman, biru kehitaman, hijau kehitaman. 


\section{Uji Kualitatif Alkaloid}

Sebanyak $2 \mathrm{~mL}$ sampel ditambahkan $8 \mathrm{~mL}$ aquadest yang telah dipanaskan selama \pm 10 menit. Filtrat disaring dan dimasukkan ke dalam tiga tabung reaksi. Tabung 1 : ditambahkan 6 tetes Pereaksi Meyer. Tabung 2 : ditambahkan 6 tetes Pereaksi Dragendrof. Tabung 3 : ditambahkan 6 tetes Pereaksi Bouchardat. Hasil positif : terdapat endapan putih pada alkaloid dengan Pereaksi Meyer, terdapat endapan jingga pada alkaloid dengan Pereaksi Dragendrof, dan terdapat endapan cokelat pada alkaloid dengan Pereaksi Bouchardat.

\section{Uji Aktivitas Antioksidan}

Uji aktivitas antioksidan ekstrak daun salam menggunakan DPPH menggunakan kontrol positif TBHQ. Uji diawali dengan pembuatan larutan ekstrak daun salam 100 ppm, 90ppm, 80 ppm, 70 ppm, 60 ppm, 50 ppm, 40 ppm, 30 ppm, $20 \mathrm{ppm}, 10 \mathrm{ppm}$. Larutan tersebut masing-masing dipipet $1 \mathrm{~mL}$ dan ditambahkan $5 \mathrm{~mL}$ larutan DPPH $1 \mathrm{mg} / 33,3 \mathrm{~mL}$. Larutan didiamkan selama 30 menit lalu diukur absorbansinya pada $517 \mathrm{~nm}$ dengan spektrofotometer UV-Vis.

\section{Uji Bilangan Peroksida}

Sebanyak 5,00 $\pm 0,05 \mathrm{~g}$ minyak goreng curah dimasukkan ke dalam erlenmeyer kemudian ditambahkan $30 \mathrm{~mL}$ larutan asam asetat-kloroform (3:2). Larutan kemudian digoyang sampai larut semua. Larutan ditambahkan 0,5 mL larutan KI. Larutan didiamkan selama 1 menit dengan digoyangkan dan ditambahkan $30 \mathrm{~mL}$ aquades. Larutan dititrasi dengan larutan $\mathrm{Na}_{2} \mathrm{~S}_{2} \mathrm{O}_{3} \quad 0,01 \mathrm{~N}$ sampai warna kuning hampir hilang. Larutan kemudian ditambahkan 0,5 mL larutan amilum 1\% hingga berwarna biru. Titrasi kedua dilakukan sampai warna biru hilang.

\section{Rancangan Percobaan}

Uji kualitatif golongan metabolit sekunder dan aktivitas antioksidan, menggunakan rancangan percobaan deskriptif. Sedangkan uji bilangan peroksida pada penelitian ini menggunakan metode Rancangan Acak Kelompok (RAK) 1 faktor yaitu, konsentrasi penambahan fraksi etil asetat terhadap minyak goreng curah.

\section{Metode Analisis}

Uji antioksidan menggunakan metode DPPH dari Molyneux (2004) untuk mendapatkan nilai $\mathrm{IC}_{50}$. Uji dilakukan terhadap fraksi etil asetat menggunakan kontrol positif TBHQ. Hasil uji akan diperoleh nilai absorbansi untuk menghitung persen penghambat.

$$
\% \text { penghambat }=\frac{(" \# \$ \# \& " \cdot()-\# \$ \$ "+,-\&)}{" \# \$ \# " \cdot()} \times 100 \%
$$

Selanjutnya hasil perhitungan dimasukkan ke dalam persamaan regresi dengan konsentrasi ekstrak (ppm) sebagai absis (sumbu X) dan nilai \% penghambat 
(antioksidan) sebagai ordinatnya (sumbu Y). Nilai $\mathrm{IC}_{50}$ dari perhitungan pada saat $\%$ penghambat sebesar 50\%. Perhitungan dengan memasukkan angka 50 ke dalam $\mathrm{y}$, nilai $\mathrm{IC}_{50}$ adalah nilai $\mathrm{x}$ hasil perhitungan tersebut.

Uji bilangan peroksida pada penelitian ini dilakukan terhadap minyak goreng curah setelah ditambahkan dengan fraksi etil asetat dengan beberapa konsentrasi dan dipanaskan sampai suhu $120 \mathrm{C}$. Pengukuran bilangan peroksida dilakukan setelah minyak dipanaskan dan didiamkan sampai suhu kamar (25 C). Bilangan peroksida dinyatakan dalam mg-equivalen peroksida dalam setiap $1000 \mathrm{~g}$ sampel.

$$
\text { Bilangan peroksida }=\frac{!^{\prime \prime} \$ \% \&() ! *+(,-) . / \% \& 0 \$ \&+(, 01222}{34 \% \& 5,6 \&,+(8)}
$$

\section{HASIL DAN PEMBAHASAN}

Sebanyak 4,8 kg daun salam dikeringkan dengan cara diangin-anginkan kemudian dihaluskan menjadi simplisia. Proses pengeringan menggunakan cara alami dengan diangin-anginkan untuk menghindari kerusakan akan metabolit sekunder yang terdapat di dalam daun salam. Proses penghalusan menjadi simplisia (serbuk) untuk meningkatkan kontak antara daun salam dengan pelarut. Pelarut yang digunakan adalah aseton dengan tujuan mendapatkan ekstrak kasar sebanyak-banyaknya. Ekstrak kasar kemudian difraksinasi menggunakan pelarut $n$-heksana, etil asetat, dan metanol. Fraksi etil asetat diambil kemudian dipekatkan. Fraksi ini kemudian diuji aktivitas antioksidannya dan bilangan peroksidanya saat diaplikasikan ke minyak curah.

\section{Uji Kualitatif Metabolit Sekunder}

Fraksi Etil asetat yang telah dipekatkan diuji secara kualitatif untuk mengetahui keberadaan metabolit sekunder golongan flavonoid, saponin, tanin, dan alkaloid. Uji dilakukan di Laboratorium Fitokimia UPT Materia Medica Batu. Hasil uji kualitatif fraksi etil asetat dapat dilihat pada Tabel 1.

Tabel 1. Hasil Uji Kualitatif Fraksi Etil Asetat Daun Salam

\begin{tabular}{llc}
\hline \multicolumn{1}{c}{ Metabolit Sekunder } & \multicolumn{1}{c}{ Hasil Pengamatan } & Kesim-pulan* \\
\hline Flavonoid & $\begin{array}{l}\text { Larutan menjadi merah } \\
\text { muda } \\
\text { Saponin }\end{array}$ & + \\
Adanya busa permanen & + \\
Tanin & $\begin{array}{l}\text { Perubahan warna menjasi } \\
\text { biru kehitaman } \\
\text { Alkaloid }\end{array}$ & + \\
Alkaloid (Dragendorf) & Muncul endapan putih & + \\
Alkaloid (Bouchardat) & Muncul endapan jingga & + \\
\hline
\end{tabular}

*) Keterangan : + menunjukkan hasil positif 
Hasil uji kualitatif fraksi etil asetat (Tabel 1) menunjukkan adanya keempat golonan flavonoid, saponin, tanin, dan alkaloid. Keempat golongan metabolit sekunder ini diketahui memiliki aktivitas antioksan sehingga hasil ini menguatkan data antioksidan dari DPPH dan uji peroksida fraksi etil asetat saat diaplikasikan ke minyak goreng curah.

\section{Aktivitas Antioksidan Fraksi Etil Asetat}

Pada penelitian ini, aktivitas antioksidan diuji dengan menggunakan metode DPPH untuk memperoleh nilai $\mathrm{IC}_{50}$. Nilai $\mathrm{IC}_{50}$ diperoleh dari perhitungan penghambatan $50 \%$ pada persamaan regresi.

Pada penelitian ini, fraksi etil asetat diuji aktivitasnya. Kontrol positif menggunakan TBHQ. Grafik hubungan antara konsentrasi dan persen penghambat fraksi etil asetat dapat dilihat pada Gambar 1 sedangkan Grafik hubungan antara konsentrasi dan persen penghambat kontrol positif TBHQ dapat dilihat pada Gambar 2.

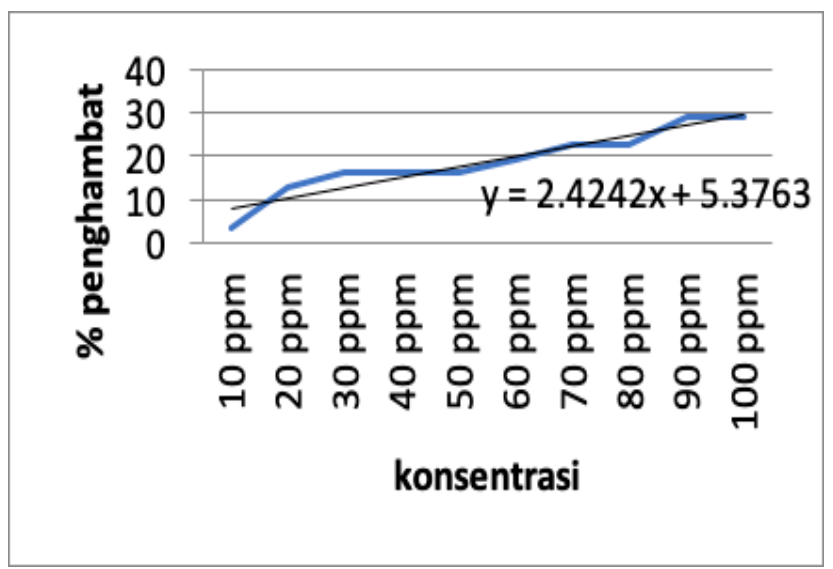

Gambar 1. Grafik Hubungan Konsentrasi dan Persen penghambat Fraksi Etil Asetat

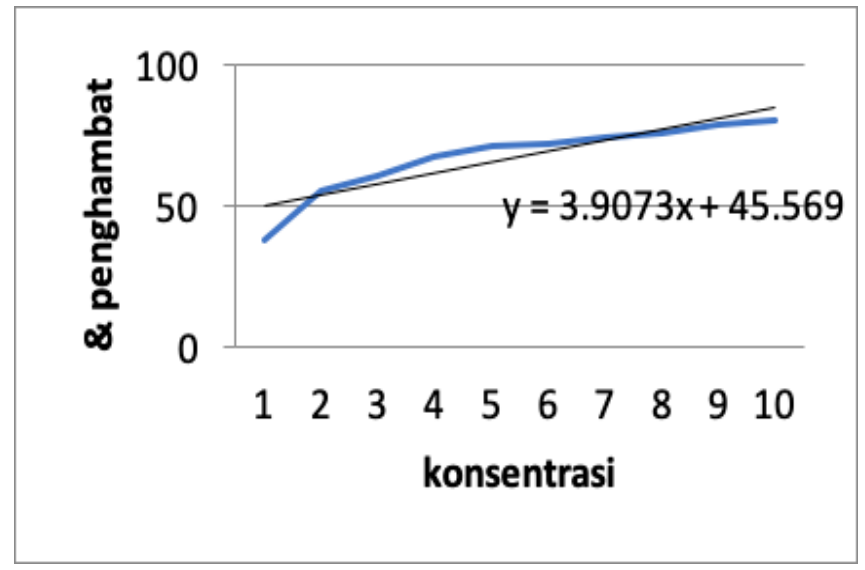

Gambar 2. Grafik Hubungan Konsentrasi dan Persen penghambat TBHQ 
Berdasarkan Gambar 1 dan Gambar 2, diperoleh persamaan regresi y = 2,4242x $+5,3763$ untuk fraksi etil asetat sedangkan control positif TBHQ diperoleh persamaan regresi $\mathrm{y}=3,9073 \mathrm{x}+45,569$. Persamaan regresi kemudian digunakan untuk menghitung $\mathrm{IC}_{50}$. Berdasarkan persamaan regresi tersebut, diketahui nilai $\mathrm{IC}_{50}$ fraksi etil asetat sebesar $18,41 \mathrm{ppm}$ dan $\mathrm{IC}_{50} \mathrm{TBHQ}$ sebesar 1,13 ppm.

Jika nilai $\mathrm{IC}_{50}$ suatu sampel berada di bawah $50 \mathrm{ppm}$ maka aktivitas antioksidannya sangat kuat, nilai $\mathrm{IC}_{50}$ berada diantara 50-100 ppm berarti aktivitas antioksidannya kuat, nilai IC $_{50}$ berada di antara $100-150 \mathrm{ppm}$ berarti aktivitas antioksidannya sedang, nilai $\mathrm{IC}_{50}$ berada di antara 150-200 ppm berarti aktivitas antioksidannya lemah, sedangkan apabila nilai $\mathrm{IC}_{50}$ berada diatas 200 ppm maka aktivitas antioksidannya sangat lemah (Molyneux, 2004). Berdasarkan pemaparan tersebut, aktivitas antioksidan fraksi etil asetat tergolong sangat kuat.

\section{Penurunan Bilangan Peroksida}

Bilangan peroksida diuji untuk mengetahui tingkat kerusakaan minyak yang dinyatakan dalam satuan meq peroksida tiap minyak. Pada penelitian ini, minyak curah ditambahkan fraksi etil asetat dengan 7 konsentrasi yang berbeda. Pengukuran bilangan peroksida dilakukan setelah minyak dipanaskan dan didiamkan sampai suhu kamar $(25 \mathrm{C})$. Kontrol positif menggunakan TBHQ. Sebagai perbandingan, pengukuran juga dilakukan pada minyak tanpa ditambahkan fraksi etil asetat. Berdasarkan analisis DMRT ( $\bullet \quad 5 \%)$, penambahan fraksi etil asetat pada minyak goreng curah berpengaruh nyata pada bilangan peroksida. Hasil uji bilangan peroksida dapat dilihat pada Tabel 2.

Tabel 2. Bilangan Peroksida Minyak Goreng Curah dengan Beberapa Perlakuan

\begin{tabular}{|c|c|c|c|}
\hline & $\begin{array}{c}\text { Konsentrasi } \\
\text { Fraksi Etil Asetat (\%b/v) }\end{array}$ & $\begin{array}{l}\text { Bilangan peroksida } \\
\left(\mathrm{meqO}_{2} / \mathrm{kg}\right)\end{array}$ & Notaci \\
\hline $\mathrm{P}_{0}$ & 0 & 7,75 & $\mathrm{~b}$ \\
\hline $\mathrm{P}_{1}$ & $0,10 \%$ & 7,25 & $\mathrm{~b}$ \\
\hline $\mathrm{P}_{2}$ & $0,20 \%$ & 6,75 & $\mathrm{~b}$ \\
\hline $\mathrm{P}_{3}$ & $0,40 \%$ & 6,88 & $\mathrm{~b}$ \\
\hline $\mathrm{P}_{4}$ & $0,60 \%$ & 6,13 & $a b$ \\
\hline $\mathrm{P}_{5}$ & $0,80 \%$ & 5,46 & $a b$ \\
\hline $\mathrm{P}_{6}$ & $1,00 \%$ & 5,04 & $a b$ \\
\hline $\mathrm{P}_{7}$ & TBHQ 0,2\% & 4,15 & $\mathrm{a}$ \\
\hline
\end{tabular}




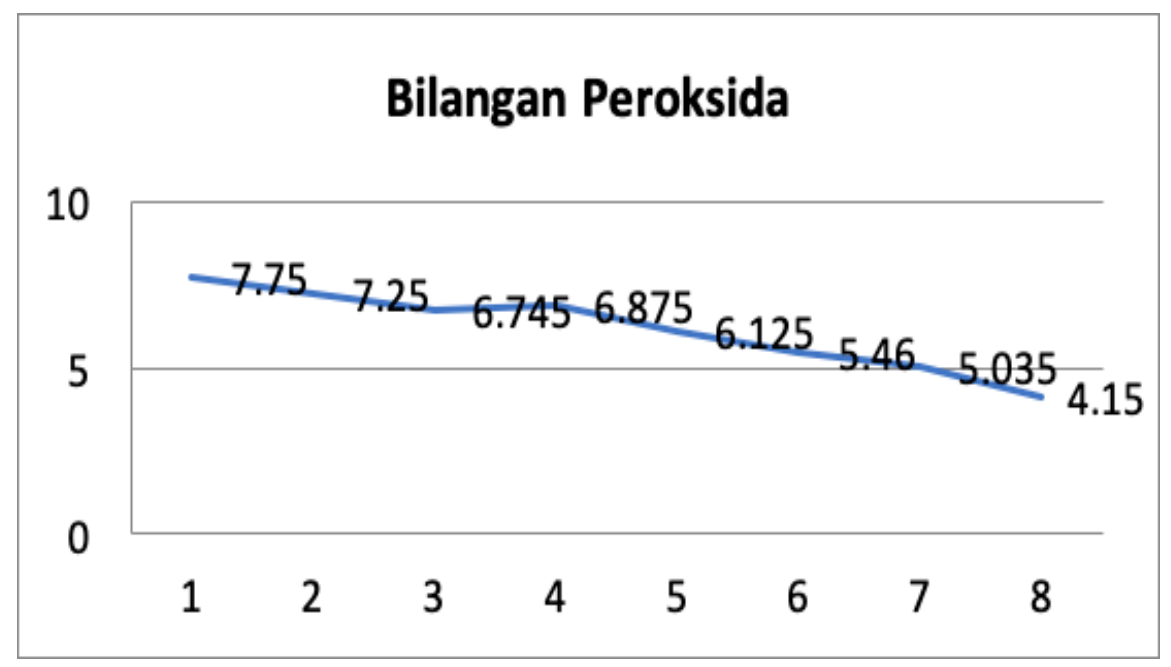

Gambar 3. Hubungan Konsentrasi dan Bilagan Peroksida

Berdasarkan data pada Tabel 2 dan Gambar 3, dapat dilihat bahwa penambahan fraksi etil asetat daun salam menyebabkan penurunan bilangan peroksida pada minyak goreng curah. Hasil uji bilangan peroksida tersebut menunjukkan bahwa penambahan fraksi etil asetat pada minyak goreng curah mampu menurunkan bilangan peroksida. Berdasarkan SNI 3741:2013, angka maksimal bilangan peroksida pada minyak adalah 10 meqO $/ 2 / k g$. Dari penelitian ini, penambahan fraksi etil asetat mampu meningkatkan kualitas minyak.

\section{KESIMPULAN}

Fraksi etil aetat daun salam terbukti memiliki aktivitas antioksidan yang tinggi, ditunjukkan dengan nilai $\mathrm{IC}_{50}$ sebesar $18,41 \mathrm{ppm}$. Penambahan fraksi etil asetat mampu menurunkan bilangan peroksida. Penambahan konsentrasi tertinggi 1,0\% mampu menurunkan bilangan peroksida minyak goreng curah menjadi 5,03. Kontrol positif TBHQ mampu menurunkan bilangan peroksida minyak goreng curah menjadi 4,14. Kemampuan antioksidan fraksi etill asetat diduga berhubungan dengan hasil posiif uji kualitatif daun salam terhadap adanya metabolit sekunder golongan flavonoid, saponin, tanin, dan alkaloid.

\section{UCAPAN TERIMAKASIH}

Ucapan terimakasih ditujukan kepada Direktorat Jenderal Penguatan Riset dan Pengembangan Indonesia terhadap dana PKM-P tahun 2018.

\section{Reference:}

Adrianto, A, W. 2012. Uji Daya Antibakteri Ekstrak Daun Salam ( Eugenia Polyantha Wight) Dalam Pasta Gigi Terhadap Pertanaman Streptococcus mutans. Jember.

Badan Pusat Statistik Indonesia. 2013. Statistik Kelapa Sawit Indonesia 2013. Nomor Publikasi 05130.1410. Jakarta.

Bahriul, Putrawan. 2004. Uji Aktivitas Antioksidan Ekstrak Daun Salam Dengan Menggunakan 1,1 Difenil-2 Pikrilhidrazil. Palu : Universitas Tadaluko 
Bera, D. L., Nag, A., "Studies on a Natural Antioxidant for Stabilization of Edible Oil and Comparison with Synthetic Antioxidant", Journal of Food Engineering, 2005.

Casarotti,S.N., Jorge,N. (2014). Antioxidant activity of rosmery extract in soybean oil under thermoxidation. Food Process, 136-145.

Fadhilla, A, R.. 2008. Analisis Kepuasan dan Loyalitas Konsumen Minyak Goreng Kemasan Merek Bimoli (Kasus: Rumah Tangga Di Kota Bogor), Skripsi, Fakultas Pertanian IPB, Bogor.

Harborne, J. B., 1987, Metode Fitokimia. Bandung : Penerbit ITB.

Hou, D.X. (2003). Potential mechanism of cancer chemoprevention by anthocyanin.

Lempang, Ika, \& Risti. 2016. Uji Kualitas Minyak Goreng Curah Dan Minyak Goreng Kemasan Di Manado. Pharmacon. Jurnal Ilmiah Farmasi.

Mailandari,M. 2012. Uji aktivitas antioksidan ekstrak daun garcinia kydia roxb dengan metode DPPH dan identifikasi senyawa kimia yang aktif. Depok : Universitas Indonesia

Molyneux, P. 2004. The use of the stable free radical diphenylpicrylhydrazyl (DPPH) for estimating antioxidant activity. Journal of Science Technology, 26(2), 211-219.

Sibuea, P. 2003. Antioksidan Senyawa Ajaib Penangkal Penuaan Dini. Yogyakarta : Sinar Harapan

Sudarsono. 2002. Tanaman Obat II : Hasil Penelitian, Sifat-sifat, dan Penggunaan. Yogyakarta: Pusat Studi Obat Tradisional UGM.

Syaefudin, 2008, Aktivitas Antioksidan Formula Ekstrak Jati Belanda, Jambu Biji dan Salam. Bogor : IPB.

Versteegh,K. 2006. Tanaman Berkhasiat Indonesia Volume 1. Bogor : IPB Press.

Widayat, Suherman dan K Haryani, 2006. Optimasi Proses Adsobsi Minyak Goreng Bekas Dengan Adsorben Zeolit Alam. Studi Pengurangan Bilangan Asam. J. Teknik Gelagar. 17, 77 - 82. Semarang : Undip.

Winarno F.G. 2004. Kimia Pangan dan Gizi. Jakarta : PT Gramedia Pustaka Utama. 